\title{
High prevalence of Helicobacter pylori metronidazole resistance in migrants to east London: relation with previous nitroimidazole exposure and gastroduodenal disease
}

Department of Epidemiology and Medical Statistics, London Hospital Medical College at QMW, London N Banatvala

L Clements

R A Feldman

Gastrointestinal Science Research Unit, London Hospital Medical College, London

G R Davies

D S Rampton

\section{Department of Oral}

Microbiology, London Hospital Medical

College, London

Y Abdi

J M Hardie

Correspondence to: Dr N Banatvala, Department of Epidemiology and Medical Statistics, London Hospital Medical College at QMW, Mile End Road, London E1 4NS.

Accepted for publication 11 March 1994

\begin{abstract}
A high prevalence of metronidazole resistance in Helicobacter pylori is reported in developing countries. This study examined whether migrants referred for diagnostic gastroscopy at a United Kingdom centre $(n=54)$, had a higher prevalence of metronidazole resistance than subjects born in the United Kingdom attending endoscopy $(n=46)$. Records of nitroimidazole treatment prescribed in the United Kingdom was obtained in 83 patients to find out if there was an association between $H$ pylori metronidazole resistance and previous ingestion of either metronidazole or tinidazole. The prevalence of metronidazole resistant isolates varied according to country of birth: Bangladesh (90\%, 27 of 30), other countries $(67 \%, 16$ of 24$)$, and United Kingdom (37\%, 17 of 46) $(p<0.001)$. Among those born in the United Kingdom, women were more likely to harbour resistant $\boldsymbol{H}$ pylori than men $(54 \%$ v $18 \%$ respectively, $p=0.01)$ and more likely to have a history of previous nitroimidazole ingestion $(41 \% \quad v \quad 11 \%$ respectively, $\mathbf{p}=0 \cdot 02$ ). Patients previously exposed to either metronidazole or tinidazole were more likely to harbour resistant strains ( $84 \%$ ( 27 of 32 ) $v 41 \%$ ( 21 or 51 ), $\mathbf{p}<\mathbf{0 . 0 0 0 1 )}$. The distribution of gastroduodenal disease, assessed endoscopically, was not affected by metronidazole resistance status.
\end{abstract}

(Gut 1994; 35: 1562-1566)

Eradication of Helicobacter pylori is effective in the treatment of associated gastritis, gastroduodenal ulceration, and preventing duodenal ulcer relapse. ${ }^{12}$ Regimens incorporating metronidazole have generally been the most effective for eradicating $H$ pylori: such treatment is, however, less effective in patients harbouring metronidazole resistant strains. ${ }^{34}$ A high prevalence of metronidazole resistance is found in developing countries. ${ }^{4}$ It has not been established (a) whether migrants carry with them the $H$ pylori metronidazole resistance rates from their country of origin and thus represent a population in whom $H$ pylori is difficult to eradicate, and (b) whether $H$ pylori resistance in itself is a marker of bacterial virulence. The population of The London Borough of Tower Hamlets, served by The
Royal London Hospital Trust (RLH), provides an opportunity to test these hypotheses as $30 \%$ of patients referred for gastroscopy are immigrants from Bangladesh or India. We compared metronidazole resistance in $\mathrm{H}$ pylori isolates from the indigenous $\mathrm{UK}$ population and those born in other countries, correlating these results with previous nitroimidazole usage and the spectrum of $H$ pylori associated gastroduodenal disease.

\section{Methods}

\section{PATIENTS}

Two hundred and seven consecutive patients attending for routine diagnostic upper gastrointestinal endoscopy at RLH were studied prospectively. Patients were asked to complete a questionnaire giving personal details including age, sex, and country of birth.

$H$ pylori metronidazole resistance was determined in patients found to be $H$ pylori gastric biopsy culture positive at endoscopy $(n=100$, $48 \%$ ).

In those patients $H$ pylori positive on gastric biopsy culture an attempt to record their previous use of metronidazole and tinidazole in the UK was made. The patient's present general practitioner was asked to obtain details of previous GP or hospital prescribed nitroimidazole treatment. The GPs were not aware whether the patients $H$ pylori was metronidazole resistant or sensitive.

Approval for these studies was obtained from Tower Hamlets ethics committee.

\section{ENDOSCOPIC CLASSIFICATION OF}

\section{GASTRODUODENAL DISEASE}

For the purposes of assessing $H$ pylori related disease, gastric and duodenal mucosal appearances were classified separately as: (a) clinically significant damage: ulceration $(\geqslant 5 \mathrm{~mm}$, with depth), or inflammation with multiple $(>3)$ erosions; (b) minor damage: mild inflammation with 0-3 erosions; (c) normal.

\section{CULTURE OF H PYLORI}

One antral gastric biopsy specimen from each patient was placed in $20 \%$ glucose transport medium, and within four hours of collection homogenised with sand (previously purified by acid) using a glass grinder. The resulting suspension was inoculated onto brain heart 
infusion agar (BHIA: Oxoid CM375) with 5\% horse defibrinated blood (Becton Dickinson, Cowley, Oxford, UK) and added $H$ pylori selective supplement (Oxoid SR147E) containing vancomycin $10 \mathrm{mg} / \mathrm{l}$, trimethoprim $5 \mathrm{mg} / \mathrm{l}$, cefsulodin $5 \mathrm{mg} / \mathrm{l}$, and amphotericin B $5 \mathrm{mg} / \mathrm{l}$. Cultures were incubated for up to five days at $37^{\circ} \mathrm{C}$ in microaerobic gaseous conditions $\left(\begin{array}{llll}5 \% & \mathrm{O}_{2} & \text { and } 10 \% & \left.\mathrm{CO}_{2}\right) \\ \end{array}\right.$ generating kit (Campylobacter system gas generating kit, Oxoid BR056A). Identity of $H$ pylori was confirmed by Gram stain and production of urease, oxidase, and catalase. ${ }^{6} 7$ Isolates were subcultured onto BHIA with $5 \%$ horse defibrinated blood, before metronidazole sensitivity was assessed.

DETECTION OF H PYLORI ON GASTRIC BIOPSY SPECIMENS BY CLO TEST

Rapid urease tests (CLO, Delta West, Australia) were performed on gastric biopsy specimens on 61 of 100 patients attending the clinic.

\section{STANDARD METRONIDAZOLE DISC SENSITIVITY} TESTING

Metronidazole sensitivity testing was performed by an investigator unaware of the clinical details.

The bacterial inoculum for sensitivity testing was prepared from a 48 hour old culture grown on BHIA with $5 \%$ horse defibrinated blood. Colonies were scraped from plates and suspended in brucella broth until a turbidity equivalent to 3 to 4 on the McFarland scale was obtained, corresponding with roughly $10^{8}$ colony forming units/ml in our laboratory. A brucella agar plate with added $5 \%$ horse defibrinated blood was streaked with a cotton wool swab saturated with the suspension. A $5 \mu \mathrm{g}$ metronidazole disc (Oxoid 039820) was placed in the centre of the plate and incubated at $37^{\circ} \mathrm{C}$ in a microaerobic atmosphere for 72 hours. A zone of $\geqslant 10 \mathrm{~mm}$ clear (diameter $25 \mathrm{~mm}$ ) of $H$ pylori around the disc was used to show metronidazole sensitivity. Control strains NCTC 12822 (sensitive) and NCTC 12823 (resistant) was included with all incubations (National Collection Type Cultures, London, UK).

\section{MINIMUM INHIBITORY CONCENTRATION SUSCEPTIBILITY TESTING}

Metronidazole minimum inhibitory concentrations were performed on 24 strains to ensure correlation between disc diffusion tests and plate dilution minimum inhibitory concentrations. The methods used have previously been described. ${ }^{8} \mathrm{~A}$ minimum inhibitory concentration of $<8 \mathrm{mg} / \mathrm{l}$ was used to indicate sensitivity. 49

\section{NITROIMIDAZOLE AVAILABILITY}

An attempt was made to record the year of introduction and over the counter availability of metronidazole and tinidazole in the
TABLE I H pylori prevalence (defined by gastric biopsy specimen culture) and age group of patients attending endoscopy at The Royal London Hospital

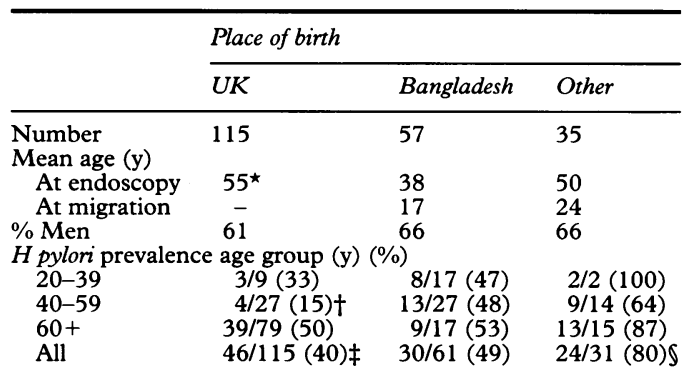

${ }^{\star} \mathrm{p}<0.0001$, mean age of UK $v$ Bangladeshi patients (Student's $t$ test); $\nmid \mathrm{p}=0 \cdot 007$, proportion of $H$ pylor $i$ stains isolated from UK $v$ overseas born patients, aged 40-59 $\left(x^{2}\right)$ $\neq \mathrm{p}=0.001$, proportion of $H$ pylori strains isolated from UK

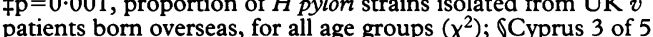
India 4 of 4 , Malta 3 of 4 , West Indies 2 of 4 , Somalia 3 of 3 , India 4 of 4 , Malta 3 of 4 , West Indies 2 of 4 , Somalia 3 of 3 , China 1 of 1 , Poland 1 of 1 , and Spain 1 of 1 .

countries the $100 \mathrm{H}$ pylori positive patients were born in. Details were obtained from Pfizer Pharmaceuticals, Sandwich, UK and Rhône Poulenc Rorer Ltd, Eastbourne, UK.

\section{STATISTICAL METHODS}

Student's $t$ test and $\chi^{2}$ tests (including Fisher's two tailed exact tests where appropriate) were performed using EPI-INFO (CDC, Atlanta, Georgia, USA) software.

\section{Results}

Table I shows the frequencies of $H$ pylori culture positivity by country of birth. Patients were divided into three groups; UK $(n=115)$, Bangladeshi $(n=61)$, and other $(n=31)$. The last group consisted of patients born in: Cyprus $(n=5)$, India $(n=4)$, Malta $(n=4)$, West Indies $(n=4)$, Somalia $(n=3)$, Greece $(n=2)$, Italy $(n=2)$, South Africa $(n=2)$, Turkey $(n=2)$, and China, Poland and Spain, one each. Results are stratified by age. UK patients were significantly older than Bangladeshis $(p<0.001)$. Most patients born in Bangladesh migrated as children or young adults (mean 17 years, range 1-46 years). Overall, $H$ pylori was less frequently cultured from patients born in the UK, compared with patients born overseas $(p=0.007)$ (Table I).

TABLE II Metronidazole resistance by country of birth and $\operatorname{sex}(n=100)$

\begin{tabular}{lccc}
\hline & Women & Men & Total \\
\hline Isolates from patients born in the & $U K^{\star}$ & & \\
Resistant & 13 & 4 & $17 \dagger$ \\
Sensitive & 11 & 18 & 29 \\
Total & 24 & 22 & 46 \\
Isolates from patients born in Bangladesh & & \\
Resistant & 7 & 20 & 27 \\
Sensitive & 2 & 1 & 3 \\
Total & 9 & 21 & 30 \\
Isolates from patients born in other countries & 8 & $16 \ddagger$ \\
Resistant & 8 & 8 & 8 \\
Sensitive & 2 & 6 & 24 \\
Total & 10 & 14 & \\
\hline
\end{tabular}

${ }^{\star} \mathrm{p}<0.001$, prevalence of $H$ pylori resistant strains from UK $v$ Bangladeshi patients $\left(\chi^{2}\right) ; \mathrm{tp}=0.01$, proportion of resistant $H$ pylori in women $v$ men $\left(\chi^{2}\right)$; $\ddagger$ India 4 of 4 , Malta 2 of 3 Somalia 3 of 3 , Cyprus 2 of 3 , West Indies 2 of 2 , Italy 0 of 2 South Africa 1 of 2 , Turkey 0 of 2 , China 1 of 1 , Poland 1 of 1 , and Spain 0 of 1 . 
TABLE III Nitroimidazole treatment before endoscopy (data obtained for 83 of $100 \mathrm{H}$ pylori culture positive patients) by sex

\begin{tabular}{lccc}
\hline & Women & Men & Total \\
\hline Patients born in the UK & $9^{\star}$ & 2 & 11 \\
Previous use & 13 & 18 & 31 \\
No previous use & 22 & 20 & 42 \\
Total & 3 & 8 & $11 \dagger$ \\
Patients born in Bangladesh & 4 & 7 & 11 \\
Previous use & 7 & 15 & 22 \\
No previous use & 6 & 4 & $10 \ddagger$ \\
Total & 2 & 7 & 9 \\
Patients born in other countries & & 11 & 19 \\
Previous use & 8 & & \\
No previous use & & & \\
Total & &
\end{tabular}

${ }^{\star} \mathrm{p}=0 \cdot 02$, proportion of men $v$ women born in the UK with a history of previous nitroimidazole use; $\mathrm{tp}=0 \cdot 05$, proportion of before endoscopy; $\neq \mathrm{p}=0.04$, proportion of others $v$ UK born before endoscopy; $\neq \mathrm{p}=0.04$, proportion of others $v$ UK
with a history of nitroimidazole use before endoscopy $\left(\chi^{2}\right.$ with a

TABLE IV H pylori metronidazole resistance according to previous nitroimidazole ingestion in the UK (data on previous ntroimidazole use obtained in 83 of $100 \mathrm{H}$ pylori culture positive patients)

\begin{tabular}{lrcc}
\hline & \multicolumn{3}{c}{ Previous metronidazole use } \\
\cline { 2 - 4 } & No & Yes & Total \\
\hline Patients born in the UK & 7 & 8 & 15 \\
Resistant & 24 & 3 & 27 \\
Sensitive & 31 & 11 & 42 \\
Total & 10 & 10 & 20 \\
Patients born in Bangladesh $\dagger$ & 1 & 1 & 2 \\
Resistant & 11 & 11 & 22 \\
Sensitive & 4 & 9 & 13 \\
Total & 5 & 1 & 6 \\
Patients born in other countries $\ddagger$ & 4 & 10 & 19 \\
Sensitive & 9 & \\
Total & & \\
\hline
\end{tabular}

${ }^{\star} \mathrm{p}=0.003, \mathrm{tp}=1.00, \neq \mathrm{p}=0.06$; proportion of $H$ pylori metronidazole resistance in those with $v$ those without a history of previous nitromidiazole treatment (for those born in the UK, Bangladesh and elsewhere), ( $\chi^{2}$ or Fisher's exact test as appropriate).

\section{METRONIDAZOLE RESISTANCE AND COUNTRY OF BIRTH}

Table II shows the relation between country of birth and metronidazole resistance in the 100 $H$ pylori isolates. Ninety per cent (27 of 30 ) of isolates from patients born in Bangladesh were metronidazole resistant, compared with $37 \%$ (17 of 46) of isolates obtained from patients born in the UK $(p<0.001)$. Of patients born in other countries $67 \%$ (16 of 24 ) of isolates were metronidazole resistant (India 4 of 4 , Malta 2 of 3, Somalia 3 of 3, Cyprus 2 of 3, West Indies 2 of 2 , Italy 0 of 2 , South Africa 1 of 2, Turkey 0 of 2, China 1 of 1 , Poland 1 of 1 , and Spain 0 of 1 ).

There was no relation between gastric

TABLE V Distribution of gastroduodenal disease (assessed endoscopically) in patients harbouring $\mathrm{H}$ pylori metronidazole resistant or sensitive strains

\begin{tabular}{|c|c|c|c|c|c|}
\hline \multirow[b]{2}{*}{ Endoscopic diagnosis ${ }^{\star}$} & \multirow[b]{2}{*}{ Total } & \multicolumn{2}{|c|}{$\begin{array}{l}\text { Metronidazole resistant } \\
\mathrm{H} \text { pylori }\end{array}$} & \multicolumn{2}{|c|}{$\begin{array}{l}\text { Metronidazole sensitive } \\
\mathrm{H} \text { pylori }\end{array}$} \\
\hline & & No & $\%$ & No & $\%$ \\
\hline \multicolumn{6}{|l|}{ Gastric } \\
\hline Clinically significant & 8 & 3 & 37 & 5 & 63 \\
\hline Minor & 47 & 29 & 62 & 18 & 38 \\
\hline Normal & 45 & 28 & 63 & 17 & 37 \\
\hline \multicolumn{6}{|l|}{ Duodena: } \\
\hline Clinical significant & 26 & 17 & 65 & 9 & 35 \\
\hline Minor & 16 & 9 & 56 & 7 & 44 \\
\hline Normal & 58 & 34 & 59 & 24 & 41 \\
\hline
\end{tabular}

*See methods for definition of endoscopic diagnoses. biopsy specimen CLO status and $H$ pylori metronidazole status ( 37 of 41 resistant strains were CLO test positive and 18 of 20 sensitive strains were CLO test positive, $\mathrm{p}=1 \cdot 0$ ).

\section{METRONIDAZOLE RESISTANCE AND PREVIOUS} NITROIMIDAZOLE TREATMENT

Records of previous metronidazole and tinidazole use in the UK were obtained in $83 \%$ (83 of 100) patients from GP records. Data were obtained from a similar proportion of each of the three ethnic subgroups: $91 \%$ (42 of 46) UK born; 73\% (22 of 30) Bangladeshi born, and $82 \%$ (19 of 24) born in other countries. Nitroimidazole treatment was more frequently prescribed in the UK, in patients born in Bangladesh, $50 \%$ (11 of 22 ) than patients born in the UK, $26 \%$ (11 of 42 ) $(p=0.05)$ (Table III). Nitroimidazole treatment was also more frequently prescribed in the $\mathrm{UK}$, in patients born in other countries, $53 \%$ (10 of 19$)$, than in patients born in the UK, $26 \%$ (11 of 42$)(p=0.04)$ (Table III).

A history of previous nitroimidazole treatment was more frequent in women, $41 \%$ (9 of 22) than men, $11 \%$ (2 of 20) in those born in the UK $(p=0.02)$ but not in those born outside the UK (Table III).

For $H$ pylori positive patients born in the UK, a history of previous nitroimidazole treatment in the UK was associated with the presence of metronidazole resistant $H$ pylori $(p=0.003)$ (Table IV). There was no relation between previous nitroimidazole treatment in the UK and presence of metronidazole resistant $H$ pylori in patients born in either Bangladesh $(p=1.00)$ or other countries $(p=0 \cdot 06)$ (Table IV).

\section{METRONIDAZOLE RESISTANCE AND SEX}

In patients born in the UK, women were significantly more likely $(p=0.01)$ to harbour resistant strains than men (Table II). Women were no more likely to harbour resistant strains than men in patients born in countries other than the UK (Bangladeshis, $p=0 \cdot 21$; other countries, $p=0.39$ ) (Table II).

\section{METRONIDAZOLE RESISTANCE AND} GASTRODUODENAL DISEASE

There was no difference in the prevalence of significant $H$ pylori associated gastric or duodenal abnormality (ulcer/multiple erosions) or minor gastritis or duodenitis between patients with $H$ pylori metronidazole sensitive and resistant isolates in any of the ethnic subgroups or in the study group overall (Table V).

\section{NITROIMIDAZOLE AVAILABILITY}

Table VI shows the year of introduction and over the counter availability of metronidazole and tinidazole in the countries the patients were born in. Metronidazole was introduced into Bangladesh in 1957 and is available as an over the counter preparation. Metronidazole was introduced in Bangladesh before any of 
TABLE VI Year of introduction and availability of 'over the counter' preparations of metronidazole and tinidazole

\begin{tabular}{|c|c|c|c|c|}
\hline \multirow[b]{2}{*}{ Country } & \multicolumn{2}{|l|}{ Metronidazole } & \multicolumn{2}{|l|}{ Tinidazole } \\
\hline & $\begin{array}{l}\text { Year of } \\
\text { introduction by } \\
\text { Rhône Poulenc Rorer }\end{array}$ & $\begin{array}{l}\text { Availability of } \\
\text { 'over the counter' } \\
\text { preparation }\end{array}$ & $\begin{array}{l}\text { Year of } \\
\text { introduction by } \\
\text { Pfizer }\end{array}$ & $\begin{array}{l}\text { Availability of } \\
\text { 'over the counter' } \\
\text { preparation }\end{array}$ \\
\hline $\begin{array}{l}\text { Bangladesh } \\
\text { China } \\
\text { Cyprus } \\
\text { India } \\
\text { Italy } \\
\text { Malta } \\
\text { Poland } \\
\text { Somalia } \\
\text { South Africa } \\
\text { Spain } \\
\text { Turkey } \\
\text { United Kingdom } \\
\text { West Indies }\end{array}$ & $\begin{array}{l}\text { 1957 } \\
\text { Mid 1970s } \\
\text { N/O } \\
1962 \\
\text { Early 1960s } \\
\text { N/O } \\
\text { N/O } \\
\text { N/O } \\
1968 \\
1961 \\
1963 \\
1960 \\
\text { N/O }\end{array}$ & $\begin{array}{l}\text { Yes } \\
\text { No } \\
\text { No } \\
\text { No }\end{array}$ & $\begin{array}{l}1978 \\
\text { Not marketed } \\
\text { Not marketed } \\
1988 \\
1979 \\
\text { Not marketed } \\
\text { Not marketed } \\
1980 \\
1974 \\
1974 \\
1991 \\
1982 \\
\text { Not marketed }\end{array}$ & $\begin{array}{l}\text { No } \\
\text { No } \\
\text { No } \\
\text { No } \\
\text { No }\end{array}$ \\
\hline
\end{tabular}

$\mathrm{N} / \mathrm{O}=$ data not obtained. of return visits to Bangladesh and therefore we cannot estimate the importance of nitroimidazole ingestion on return visits to Bangladesh. In addition, however, Bangladeshi patients had significantly higher metronidazole usage in the UK than the indigenous population $(50 \% v$ $26 \%$ ); thus the high metronidazole resistance rate may be attributable in part to their metronidazole ingestion since migration.

Within the UK born population, we found that women were significantly more likely to harbour resistant strains; this confirms previous reports. ${ }^{311}$ It has been shown that in patients with $H$ pylori infection, women are more likely than men to have been treated for non- $H$ pylori disease with nitroimidazoles. ${ }^{11}$ This sex difference in metronidazole use further supports the hypothesis that previous nitroimidazole treatment for non- $H$ pylori related disease is a risk factor for $H$ pylori metronidazole resistance. ${ }^{11}$

$H$ pylori was more frequently isolated from patients born outside the UK. There was no evidence that metronidazole resistant strains were more easily isolated than sensitive strains as there was no relation between metronidazole resistance and gastric biopsy specimen rapid urease test result.

Acquisition of antimicrobial resistance has been associated with both increased and decreased bacterial virulence. ${ }^{12-16}$ For $H$ pylori we found the distribution of significant gastroduodenal disease in metronidazole sensitive and resistant strains to be similar. These results do not support an associated between acquisition of metronidazole resistance and $H$ pylori virulence.

While there is no universally accepted treatment, regimens for $H$ pylori eradication including a nitroimidazole (usually metronidazole) are generally the most effective. ${ }^{17} \mathrm{H}$ pylori eradication treatment is less successful in subjects harbouring metronidazole resistant strains. $^{3418}$ The high frequency of metronidazole resistant strains in our population, particularly in ethnic minority groups, constitutes a therapeutic problem to which there is as yet no clear solution. The metronidazole resistance rates for our UK born population are higher than in previous reports. ${ }^{7}$ This may be explained by the comparatively high rate of nitroimidazole use in our UK born subgroup. An alternative but untested hypothesis is that imported resistant strains have infected subjects born in the UK.

In conclusion, this study has shown that subjects born in developing countries, infected with $H$ pylori, and now living in the UK, have a high prevalence of metronidazole resistance. In addition, metronidazole resistance was more frequent when patients had a history of previous nitroimidazole treatment. The spectrum of gastroduodenal abnormality associated with $H$ pylori infection seems independent of metronidazole resistance status.

We thank Professor D I Edwards and Dr G Urwin for their valuable comments during preparation of this manuscript. We thank Pfizer Pharmaceuticals, Sandwich, UK and Rhône Poulenc Rorer, Eastbourne, UK for assistance in determining nitroimidazole availability in the countries listed

Funding for this work was provided by The Special Trustees ingested metronidazole without prescription. ${ }^{10}$ It therefore seems probable that a high proportion of Bangladeshi patients will have been exposed to metronidazole before migrating to the UK. We do not have data on the frequency 
of The Royal London Hospital and Lederle Pharmaceuticals. Some of these data have been published in abstract form: Gut 1993; 34 (suppl): S37 and Gastroenterology 1993; 104: A37.

1 Marshall BJ, Goodwin CS, Warren JR, Murray R, Blincow Ed, Blackbourn SJ, et al. Prospective double-blind trial of duodenal ulcer relapse after eradication of Campylobacter pylori. Lancet 1988; ii: $1437-42$.

2 Rauws EA, Tytgat GN. Cure of duodenal ulcer associated with eradication of Helicobacter pylori. Lancet 1990; 335: 1233-5.

3 Rautelin H, Seppala K, Renkonen OV, Vainio U, Kosunen TU. Role of metronidazole resistance in therapy of TU. Role of metronidazole resistance in therapy of Helicobacter pylori infecti

4 Glupczynski Y, Burette A, De Koster E, Nyst JF, Deltenre $M$, Cadranel S, et al. Metronidazole resistance in Helicobacter pylori [Letter]. Lancet 1990; 335: 976-7.

5 Megraud F, Bonnet F, Garnier M, Lamouliatte H Characterization of 'Campylobacter pyloridis' by culture, enzymatic profile, and protein content. $\mathcal{f}$ Clin Microbiol 1985; 22: 1007-10.

6 Barrow GI, Feltham RKA, eds. Cowan and Steel's manual for the identification of medical bacteria. 3rd ed. Cambridge: Cambridge University Press, 1993.

7 European Study Group on Antibiotic Susceptibility of Helicobacter pylori. Results of a multicentre European survey in 1991 of metronidazole resistance in survey in 1991 of metronidazole resistance in 11: $777-81$.

8 A guide to sensitivity testing. Working party on antibiotic sensitivity testing of the British Society for Antimicrobial Chemotherapy (section 3.1.3.1). F Antimicrob Chemother 1991; 27 (suppl D): 1-50

9 National Committee for Clinical Laboratory Standards. Methods for antimicrobial susceptibility testing of anaerobic bacteria. Approved standard M11-A2. Villanova, Penna: NCCLS, 1993.

10 Azhar MA, Ahasan HAMN, Chowdhury MAJ, Rafiqueuddin AKM. Over the counter drugs in Bangladesh [Letter]. BM7 1993; 307: 1422.

11 Becx MC, Janssen AJ, Clasener HA, de Koning RW. Metronidazole-resistant Helicobacter pylori [Letter] Lancet 1990; 335: 539-40.

2 Bryan LE, O'Hara K, Wong S. Lipopolysaccharide changes in impermeability type aminoglycoside resistance in Ps intimicrob Agents Chemother 1984; 26: 250-5.

13 Dorman CJ, Chatfield S, Higgins CF, Haywood C, Dougan $G$. Characterisation of porin and Omp R mutants of a vir$G$. Characterisation of porin and Omp R mutants of a virulent strain of Salmonella typhimurium: Omp R mutants 14 Ravizzola G, Pirali F, Paolucci A. Reduced virulence in ciprofloxacin-resistant variants of Ps aeruginosa strains. f Antimicrob Chemother 1987; 20: 825-9.

5 Musher DM, Baughn RE, Templton GB, Minuth JN. Emergence of variant forms of $S$ aureus after exposure to gentamicin and infectivity of variants in experimental animals. F Infect Dis 1977; 136: 360-9.

16 Coia JE, Browning L, Haines L, Birkbeck TH, Platt DJ. Comparison of enterotoxins and haemolysins produced by methicillin-resistant (MRSA) and sensitive (MSSA) S aureus. 7 Med Microbiol 1992; 36: 164-71.

17 Marshall BJ. Treatment of Helicobacter pylori. In: Marshall BJ, McCallum RW, Guerrant RL, eds. Helicobacter pylori in peptic ulceration and gastritis. Oxford: Blackwell in peptic ulceration and

18 Bell GD, Powell K, Burridge SM, Pallecaros A, Jones PH, Gant PW, et al. Experience with 'triple' anti-Helicobacter pylori eradication therapy: side effects and the importance of testing the pre-treatment bacterial isolate for metronidazole resistance. Aliment Pharmacol Ther 1992; 6: $427-35$. 